\title{
STUDI PELAKASANAAN PELAYANAN SWAMEDIKASI BEBERAPA APOTEK KOTA KENDARI
}

\author{
Asriullah Jabbar ${ }^{1 *}$, Nurjannah $^{2}$, Mus Ifayah $^{3}$ \\ Fakultas Farmasi Universitas Halu Oleo Kendari ${ }^{1}$ \\ Rumah Sakit Umum Bahteramas Provinsi Sulawesi Tenggara ${ }^{2}$ \\ STIKES Mandala Waluya Kendari, Program Studi Farmasi ${ }^{3}$ \\ Email : asriullah.jabbar@gmail.com
}

\begin{abstract}
ABSTRAK
Swamedikasi adalah suatu upaya masyarakat untuk mengobati diri sendiri. Berdasarkan data Survei Sosial Ekonomi Nasional (Susenas) menunjukkan bahwa lebih dari 66\% masyarakat melakukan pengobatan sendiri (Swamedikasi). Keterbatasan pengetahuan tentang obat dapat menyebabkan rentannya masyarakat terhadap informasi komersial obat, sehingga memungkinkan terjadinya pengobatan yang tidak rasional jika tidak diimbangi dengan pemberian informasi yang benar. Tujuan penelitian ini untuk mengetahui pelaksanaan Pelayanan swamedikasi di Apotik Kota Kendari. Penelitian menggunakan desain Purposive sampling. Data dikumpulkan dengan menggunakan kuesioner. Penelitian bertempat di 30 Apotek Kota Kendari. Hasil Penelitian menunjukkan pelayanan Swamedikasi beberapa Apotek Kota Kendari dari 3 kategori adalah 63,34\%. Persentase Jenis Obat dalam Pelayanan Swamedikasi beberapa Apotik Kota Kendari adalah Golongan Obat berdasarkan Penggolongannya adalah obat bebas $(31 \%)$, obat bebas terbatas $(26 \%)$, obat keras (18\%), obat herbal (18\%), lain-lain (7\%). Penggolongan obat berdasarkan penyakit adalah Espektoran/Antitusif (17,5\%), Analgetik/Antipiretik (18,7\%), Anti Emetik (7,5\%), Anti Inflamasi (14,7\%), Gastritis (14\%), Anti Histamin (12,3\%), Anti Diare $(12,3 \%)$, dan Lain-lain (3\%). Persentase Jenis Edukasi dalam pelayanan Swamedikasi beberapa Apotik Kota Kendari yaitu dosis obat/Interval obat $(19,2 \%)$, Cara penggunaan (19,4\%), Indikasi (18,4\%), Kontra Indikasi (11,2\%), Efek samping $(13 \%)$, Interaksi obat dengan obat $(8,7 \%)$, interaksi obat dengan makanan $(7,3 \%)$, dan Lain-lain (2,8\%).
\end{abstract}

Kata kunci : Swamedikasi, Apotek, Edukasi

\begin{abstract}
Self medication is a community effort to self-medicate. Based on data from the National Socioeconomic Survey (SUSENAS) lack of knowledge about the drug may cause vulnerability of society against drug commercial information, thus enabling the treatment of irrational if not balanced with the provision of correct information. The purpose of the study is to examine the implementation of the Services Pharmacies self medication in Kendari. This study using purposive sampling design. Data were
\end{abstract}


collected using a questionnaire. This study took place in 30 pharmacies Kendari city. Based on the research results obtained Percentage Pharmacy Services Self medication some of Kendari from 3 category is 63.34\%. Percentage Type Drugs in Services Self medication several Pharmacies Kendari is the group Drugs based classification is a drug-free (31\%), free drug is limited (26\%), prescription drugs (18\%), herbal remedies (18\%), others (7\%). Classification of drugs by disease is Espektoran / Antitusif (17.5\%), Analgesic / Antipyretic (18.7\%), Anti-emetic (7.5\%), Anti-Inflammatory (14.7\%), gastritis (14\%), Anti histamine (12.3\%), Anti diarrhea (12.3\%), and other (3\%). Percentage of Educational type in service several Pharmacies Kendari Self medication is the dose of drug / drug Interval (19.2\%), How to use (19.4\%), indication (18.4\%), Contraindications (11.2\%), securities side (13\%), drug-drug interaction (8.7\%), drug interactions with food (7.3\%), and other (2.8\%).

Keywords : Self Medication, pharmacy service, Education.

\section{PENDAHULUAN}

Kesehatan adalah keadaan sehat, baik secara fisik, mental, spiritual maupun sosial yang memungkinkan setiap orang untuk hidup produktif secara social dan ekonomis (UU No.36, 2009). Apotek adalah sarana pelayanan kefarmasian tempat dilakukan praktik kefarmasian oleh Apoteker (Permenkes, 2014).

Apotek ialah pelayanan resep, penyiapan obat, informasi obat, konseling, monitoring penggunaan obat, promosi dan edukasi, pelayanan residensial atau home care (Permenkes, 2014). Pengobatan sendiri (self medication) adalah adalah pemilihan dan penggunaan obat modern, herbal, maupun obat tradisional oleh seorang individu untuk mengatasi penyakit atau gejala penyakit (WHO, 1998). Pengobatan sendiri termasuk memperoleh obatobatan tanpa resep, membeli obat berdasarkan resep lama yang pernah diterima, berbagi obat-obatan dengan kerabat atau anggota lingkaran social seseorang atau menggunakan sisa obat-obatan yang disimpan dirumah (Adhikary, 2014). Upaya masyarakat untuk mengobati diri sendiri dikenal dengan istilah self medication (Depkes, 2008).

Berdasarkan Data Survei Sosial Ekonomi Nasional (Susenas) menunjukkan bahwa lebih dari $66 \%$ masyarakat melakukan pengobatan 
sendiri (self medication). Sedangkan Hasil Riset Kesehatan Dasar tahun 2013 menunjukkan bahwa 35,2 \% masyarakat Indonesia menyimpan obat di rumah angga, baik diperoleh dari resep dokter maupun dibeli sendiri secara bebas. Proporsi masyarakat yang menyimpan obat keras tanpa resep mencapai $81,9 \%$, di antaranya termasuk antibiotik (Depkes, 2013). Data ini membuktikan bahwa sejumlah besar masyarakat melakukan self medication. Untuk itu harus diimbangi dengan informasi yang memadai, sehingga tidak terjadi kesalahan.

Pengobatan sendiri biasanya dilakukan untuk mengatasi keluhan dan penyakit ringan yang banyak dialami masyarakat, seperti demam, nyeri, batuk, flu, maag, cacingan, diare, penyakit kulit dan lain-lain (Depkes, 2006). Pelaksanaan self medication didasari oleh pemikiran bahwa pengobatan sendiri cukup untuk mengobati masalah kesehatan yang dialami tanpa melibatkan tenaga kesehatan (Fleckenstein, dkk., 2011). Alasan lain adalah karena semakin mahalnya biaya pengobatan ke dokter, tidak cukupnya waktu yang dimiliki untuk berobat, atau kurangnya akses ke fasilitas-fasilitas kesehatan (Atmoko dan Kurniawati, 2009; Gupta, dkk., 2011).

Self medication harus dilakukan sesuai dengan penyakit yang dialami. Pelaksanaannya harus memenuhi kriteria penggunaan obat yang rasional, antara lain ketepatan pemilihan obat, ketepatan dosis obat, ada tidaknya efek samping, tidak adanya kontra indikasi, tidak adanya interaksi obat, dan tidak adanya polifarmasi (Depkes RI., 2008).

Keterbatasan pengetahuan tentang obat dapat menyebabkan rentannya masyarakat terhadap informasi komersial obat, sehingga memungkinkan terjadinya pengobatan yang tidak rasional jika tidak diimbangi dengan pemberian informasi yang benar (Purwanti, dkk., 2004).

\section{METODE PENELITIAN}

Jenis penelitian yang digunakan adalah penelitian deskriptif 
dilakukan dengan tujuan untuk mendiskripsikan atau menggambarkan fakta-fakta mengenai populasi secara sistematis, dan akurat.

\section{HASIL DAN PEMBAHASAN}

\section{Karakteristik Responden}

Tabel 1. Karakteristik Distribusi responden Berdasarkan Jenis Kelamin

\begin{tabular}{ccc}
\hline $\begin{array}{c}\text { Jenis } \\
\text { kelamin }\end{array}$ & $\begin{array}{c}\text { Frekuensi } \\
(\mathbf{F})\end{array}$ & $\begin{array}{c}\text { Presentase } \\
(\mathbf{\%})\end{array}$ \\
\hline Laki-laki & 3 & 10 \\
Perempuan & 27 & 90 \\
\hline Jumlah & 30 & 100 \\
\hline
\end{tabular}

Tabel 2. Karakteristik Distribusi Responden Berdasarkan lama bekerja sebagai Apoteker di Beberapa apotek Kota Kendari Tahun 2016

\begin{tabular}{ccc}
\hline $\begin{array}{c}\text { Lama Bekerja } \\
\text { Sebagai }\end{array}$ & $\begin{array}{c}\text { Frekuensi } \\
\text { (F) }\end{array}$ & $\begin{array}{c}\text { Presentase } \\
\text { (\%) }\end{array}$ \\
Apoteker & & \\
\hline <1Tahun & 4 & 13.3 \\
1-5Tahun & 15 & 50 \\
6-10Tahun & 9 & 30 \\
>10 Tahun & 2 & 6,7 \\
\hline Jumlah & 30 & 100 \\
\hline
\end{tabular}

Tabel 3. Karakteristik

Distribusi Responden Berdasarkan Lama Jam Kerja Di Beberapa Apotek Kota Kendari Tahun 2016

\begin{tabular}{ccc}
\hline $\begin{array}{c}\text { Lama Jam } \\
\text { Kerja }\end{array}$ & $\begin{array}{c}\text { Frekuensi } \\
(\mathbf{F})\end{array}$ & $\begin{array}{c}\text { Presentase } \\
(\mathbf{\%})\end{array}$ \\
\hline 1-5 Jam & 19 & 63,3 \\
6-10 Jam & 10 & 33,4 \\
>10 Jam & 1 & 3,3 \\
\hline Jumlah & 30 & 100
\end{tabular}

\section{Analisis Deskriptif}

\section{a. Persentase Pelayanan Self medication}

Tabel 4. Distribusi responden berdasarkan jumlah pelayanan self medication perhari beberapa Apotek di Kota Kendari yang pemilik sarana Apotiknya adalah Apoteker

\begin{tabular}{ccc}
\hline $\begin{array}{c}\text { Pelayanan } \\
\text { Self } \\
\text { medication }\end{array}$ & $\begin{array}{c}\text { Frekuensi } \\
\text { (F) }\end{array}$ & $\begin{array}{c}\text { Presentase } \\
(\mathbf{\%})\end{array}$ \\
\hline$<10$ & 7 & 70 \\
$20-50$ & 3 & 30 \\
$50-100$ & 0 & 0 \\
$100-150$ & 0 & 0 \\
$150-200$ & 0 & 0 \\
\hline Jumlah & 10 & 100 \\
\hline
\end{tabular}

Tabel 5. Distribusi Responden Berdasarkan jumlah Pelayanan Self medication perhari beberapa Apotek Di Kota Kendari yang pemilik sarana Apotiknya adalah Dokter

\begin{tabular}{ccc}
\hline $\begin{array}{c}\text { Pelayanan } \\
\text { Self } \\
\text { medication }\end{array}$ & $\begin{array}{c}\text { Frekuensi } \\
\text { (F) }\end{array}$ & $\begin{array}{c}\text { Presentase } \\
\mathbf{( \% )}\end{array}$ \\
\hline$<10$ & 5 & 50 \\
$20-50$ & 3 & 30 \\
$50-100$ & 2 & 20 \\
$100-150$ & 0 & 0 \\
$150-200$ & 0 & 0 \\
\hline Jumlah & 10 & 100 \\
\hline
\end{tabular}

Warta Farmasi Vol.6 No.1, ISSN 2089-712X 
Tabel 6. Distribusi Responden Berdasarkan jumlah Pelayanan Self medication perhari beberapa Apotek Di Kota Kendari yang pemilik sarana Apotiknya Selain Apoteker dan Dokter

\begin{tabular}{ccc}
\hline $\begin{array}{c}\text { Pelayanan } \\
\text { Self }\end{array}$ & $\begin{array}{c}\text { Frekuensi } \\
\text { (F) }\end{array}$ & $\begin{array}{c}\text { Presentase } \\
(\%)\end{array}$ \\
\hline$<$ dication & & 70 \\
$20-50$ & 7 & 30 \\
$50-100$ & 0 & 30 \\
$100-150$ & 0 & 0 \\
$150-200$ & 0 & 0 \\
\hline Jumlah & 10 & 100 \\
\hline
\end{tabular}

Tabel 7. Jumlah pelayanan self medication perhari beberapa apotek Di Kota Kendari

\begin{tabular}{cc}
\hline Pemilik Sarana Apotek & Presentase (\%) \\
\hline Apoteker & 70 \\
Dokter & 50 \\
Selain Dokter dan & 70 \\
Apoteker & \\
\hline Rata-rata & $\mathbf{6 3 . 3 4}$ \\
\hline
\end{tabular}

\section{b. Persentase Jenis Obat Yang Diberikan Saat Pelayanan Self Medication}

Tabel 8. Distribusi Responden Berdasarkan Penggolongan Obat yang diberikan pada saat Pelayanan Self medication di beberapa Apotik Kota Kendari

\begin{tabular}{cc}
\hline Golongan obat & Presentase (\%) \\
\hline Obat bebas & 31 \\
Obat bebas terbatas & 26 \\
Obat keras & 18 \\
Obat herbal & 18 \\
Lain-lain & 7 \\
\hline Jumlah & $\mathbf{1 0 0}$ \\
\hline
\end{tabular}

Tabel 9. Distribusi Responden Berdasarkan Penggolongan Obat yang diberikan pada saat Pelayanan Self medication di beberapa Apotik Kota Kendari

\begin{tabular}{cc}
\hline $\begin{array}{c}\text { Golongan berdasarkan } \\
\text { penyakit }\end{array}$ & $\begin{array}{c}\text { Presentase } \\
\mathbf{( \% )}\end{array}$ \\
\hline Ekspektoran/Antitusif & 17,5 \\
Analgetik/Antipiretik & 18,7 \\
Anti emetik & 7,5 \\
Anti Inflamasi & 14,7 \\
Gastritis & 14 \\
Anti histamin & 12,3 \\
Anti diare & 12,3 \\
Lain-lain & 3 \\
\hline Jumlah & $\mathbf{1 0 0}$ \\
\hline
\end{tabular}

\section{c. Persentase Jenis Edukasi Yang Diberikan Saat Pelayanan Self Medication}

Tabel 10. Distribusi Responden Berdasarkan jenis edukasi yang diberikan pada saat Pelayanan Self medication di beberapa Apotik Kota Kendari 


\begin{tabular}{lc}
\hline \multicolumn{1}{c}{ Jenis edukasi } & Presentase (\%) \\
\hline Dosis obat/interval obat & 19,2 \\
Cara penggunaan & 19,4 \\
Indikasi & 18,4 \\
Kontra indikasi & 11,2 \\
Efek samping & 13 \\
Interaksi obat dengan obat & 8,7 \\
Interaksi obat dengan makanan & 7,3 \\
Lain-lain & 2,8 \\
\hline \multicolumn{1}{c}{ Jumlah } & 100 \\
\hline
\end{tabular}

Berdasarkan tabel 3, diketahui bahwa Lama Jam Kerja di Apotek dari 30 respondendidapatkan responden yang paling banyak adalah Apoteker bekerja di Apotek selama 1-5 jam sebanyak 19 orang $(63,3 \%)$. Harrington (2001) menyatakan bahwa lamanya jam kerja berlebih dapat meningkatkan human error atau

Berdasarkan tabel 1, diketahui bahwa jenis kelamin dari 30 responden yang terdiri dari laki-laki dan perempuan sehingga dapat diketahui resonden yang paling banyak adalah perempuan $(90 \%)$ responden dan responden yang paling sedikit adalah responden laki-laki sebanyak $(10 \%)$

Berdasarkan tabel 2, diketahui bahwa dari 30 responden yang terdiri dari responden yang telah bekerja sebagai APAdiketahui resonden yang paling banyak adalah lama bekerja sebagai apoteker di Apotek Selama 15 tahun yaitu 15 (50\%) responden. Hal ini dapat diketahui bahwa Apoteker pengelola Apotik beberapa Apotik Kota Kendari dapat dikatakan telah berpengalama dan memiliki wawasan yang baik di bidangnya. Berdasarkan pendapat (Notoatmodjo, 2007) tentang lama kerja, Lama kerja kategori baru $\leq$ 3 Tahun dan $>3$ Tahun dikategorikan lama, dan semakin lama seseorang telah bekerja semakin berpengalaman dan memiliki wawasan yang baik dibidangnya. kesalahan kerja karena kelelahan yang meningkat dan jam tidur yang berkurang.

Pada pertanyaan No 1, 2 dan 3 berdasarkan variabel persentase pelayanan self medication diketahui bahwa seluruh reponden mengetahui arti self medication dan 29 responden $(96,7 \%)$ melaksanakan self medication secara langsung atau tidak melalui telpon dan SMS. Pada pertanyaan No 4 diketahui bahwa 24 resppnden (80\%). Berdasarkan tabel 4, 5, 6 dan 7 berdasarkan jumlah pelayanan self medication dari 30 responden dikategorikan menjadi 3 kategori apotik yang pemilik sarana apoteknya adalah Apoteker, PSA nya Dokter, PSA nya selain Apoteker dan Dokter, masing-masing 10 responden didapatkan bahwa jumlah pelayanan self medication di Apotek Pemilik Sarana Apotiknya Apoteker melakukan pelayanan self medication terbanyak adalah $<10$ orang perhari 7 orang (70\%), yang Pemilik Sarana Apotiknya Dokter melakukan pelayanan self medication $<10$ orang 
perhari 5 orang (50\%), Pemilik Sarana Apotiknya Selain Apoteker dan dokter melakukan pelayanan self medication $<10$ orang perhari 7 orang $(70 \%)$ dan secara keseluruhan diperoleh jumlah pelayanan self medication adalah 63,34\%.

Pada pertanyaan Penelitian No 1 pada Variabel Persentase Jenis Obat dalam Pelayanan Self medication diketahui bahwa seluruh responden mengetahui Jenis Obat apa saja yang diberikan dalam Pelayanan Self medication. Berdasarkan tabel 8 dan 9 menunjukkan persentase penggolongan obat yang diberikan pada saat pelayanan self medication di beberapa apotik Kota Kendari adalah obat bebas (31\%), obat bebas terbatas $(26 \%)$, obat keras $(18 \%)$, obat herbal (18\%), lain-lain (7\%).Berdasarkan tabel 8 dan grafik diatas menunjukkan persentase penggolongan obat berdasarkan penyakit yang diberikan pada saat pelayanan self medication di beberapa apotik Kota Kendari adalah Espektoran/Antitusif $\quad(17,5 \%)$, Analgetik/Antipiretik (18,7\%), Anti Emetik (7,5\%), Anti Inflamasi (14,7\%), Gastritis (14\%), Anti Histamin (12,3\%), Anti Diare (12,3\%), dan Lain-lain (3\%).

Pada pertanyaan Penelitian No 1 pada Variabel Persentase Jenis Edukasi dalam Pelayanan Self medication diketahui bahwa seluruh responden mengetahui Materi Edukasi apa saja yang diberikan dalam Pelayanan Self medication. Berdasarkan tabel 10 dan grafik diatas menunjukkan persentase penggolongan obat berdasarkan penyakit yang diberikan pada saat pelayanan self medication di beberapa apotik Kota Kendari adalah dosis obat/Interval obat $(19,2 \%)$, Cara penggunaan $(19,4 \%)$, Indikasi (18,4\%), Kontra Indikasi (11,2\%), Efek samping (13\%), Interaksi obat dengan obat $(8,7 \%)$, interaksi obat dengan makanan(7,3\%), dan Lain-lain $(2,8 \%)$.

\section{Kesimpulan}

1. Persentase Pelayanan Self medication beberapa Apotek Kota Kendari dari 3 kategori adalah 63,34\%.

2. Persentase Jenis Obat dalam Pelayanan Self medication beberapa Apotik Kota Kendari dari 2 macam Golongan Obat adalah Golongan Obat berdasarkan Penggolongannya adalah obat bebas (31\%), obat bebas terbatas $(26 \%)$, obat keras $(18 \%)$, obat herbal $(18 \%)$, lainlain (7\%). Penggolongan obat berdasarkan penyakit adalah Espektoran/Antitusif $\quad(17,5 \%)$, Analgetik/Antipiretik (18,7\%), Anti Emetik (7,5\%), Anti Inflamasi (14,7\%), Gastritis (14\%), Anti Histamin (12,3\%), 
Anti Diare (12,3\%), dan Lain-lain (3\%).

3. Persentase Jenis Edukasi dalam pelayanan Self medication beberapa Apotik Kota Kendari yaitu dosis obat/Interval obat $(19,2 \%)$, Cara penggunaan (19,4\%), Indikasi (18,4\%), Kontra Indikasi $(11,2 \%)$, Efek samping (13\%), Interaksi obat dengan obat $(8,7 \%)$, interaksi obat dengan makanan(7,3\%), dan Lain-lain $(2,8 \%)$.

\section{DAFTAR PUSTAKA}

Adhikary, M., Poornima, B., Saudan, S., dan Chetan,K. (2014). Study of Self-Medication Practice and Its Determinants Among College Students of Delhi University North Campus, New Delhi, India: International Journal of Medical Science and Public Health 2014. 3(4): 406.

Anief, Moh. (1997). Formulasi Obat Topika Dengan Dasar Penyakit Kulit. Cetakan Pertama.Yogyakarta: Penerbit Gadjah Mada University Press.

Atmoko, W.B., \& Kurniawati, I., 2009. Self medication : Sebuah Respon Realistik Perilaku Konsumen di Masa Krisis. Jurnal Bisnis dan Kewirausahaan, Vol. 2 No. 3, ISSN : 1979-0333. Semarang : Universitas Diponegoro.
Depkes RI, 2006, Pedoman Penggunaan Obat bebas dan Obat Bebas Terbatas, Direktorat bina Farmasi Komunitas dan Klinik Ditjen Bina Kefarmasian dan Alat Kesahatan, Jakarta.

Depkes R.I., 2008. Profil Kesehatan Indonesia. Jakarta.

Depkes RI. 2013. Riset Kesehatan Dasar. Jakarta: Badan Penelitian dan pengembangan Kesehatan Kementrian Kesehatan RI.

FIP, 1999. Joint Statement By The International harmaceutical Federation and The World SelfMedication Industry: Responsible Self-Medication. FIP \& WSMI, p.1-2

Fleckenstein, A.E., Hanson, G. R. \& Venturelli, P. J. 2011. Drugs and society(11 thed). Jones and Bortlett Publisher : USA, dalam jurnal penelitian Dian Hermawati : Pengaruh Edukasi Terhadap Tingkat Pengetahuan dan Rasionalitas Penggunaan Obat Self medication Pengunjung di dua Apotek Kecamatan Cimanggi., Depok.

Gupta, P., Bobhate, P., dan Shrivastava, S. (2011). Determinants of self medication practices in an urban slum community. Asian Journal Pharmaceutical and Clinical Research. 4(3). Tropical Journal 
of Pharmaceutical Research. August 2012; 11(4): 684.

Indonesia. Undang-Undang Tentang Kesehatan, UU Nomor 36 Tahun 2009 Lembaran Negara Republik Indonesia No. 144 Tahun 2009, Tambahan Lembaran Negara Republik Indonesia No. 5063

Notoatmodjo, S. 2010. Metodologi Penelitian Kesehatan. Jakarta : Rineka Cipta

Nursalam. 2003. Konsep \& Penerapan Metodologi Penelitian Ilmu Keperawatan: Pedoman Skripsi, Tesis, dan Instrumen Penelitian Keperawatan. Jakarta. Salemba Medika.

Osemene, K, P., dan A, Lamikanra. (2012). A Study of the Prevalence of SelfMedication Practice among University Students in Southwestern Nigeria.

Permenkes, 2014, Peraturan Menteri Kesehatan Republik Indonesia Nomor 35 Tahun 2014, Standar Pelayanan Kefarmasian Di Apotek.

Peraturan Pemerintah RI. 2009. Peraturan Pemerintah Republik Indonesia Nomor 51 Tahun 2009 Tentang Pekerjaan Kefarmasian.
Purwanti, A., Harianto., dan Supardi, S. (2004). Gambaran Pelaksanaan Standar Pelayanan Farmasi di apotek DKI Jakarta tahun 2003. Majalah Ilmu Kefarmasian. 1(2): 102,105 .

Saryono. (2011). Metodologi Penelitian Kesehatan. Yogyakarta: Mitra Cendikia Press.

Sugiyono, (2011). Metode Penelitian Pendidikan (Pendekatan Kuantitatif, Kualitatif, dan R\&D); Alfabeta. Bandung.

Supardi, S., dan Notosiswoyo, M, 2005. Pengobatan sendiri sakit kepala, demam, batuk dan pilek pada masyarakat desa Ciwalen, Kecematan Warungkondang, Kabupaten Cianjur, Jawa Barat. Majalah Ilmu Kefarmasian, Vol II No. 3.Widodo, Rahayu. 2004. Panduan Keluarga Memilih dan Menggunakan Obat. Yogyakarta: Kreasi Wacana.

Tan Hoan Tjay \& Kirana Rahardja. 1993, Self medication. PT. Elex Media Komputindo. Jakarta.

WHO, 1998. The Role of The Pharmacist in Self-Care and Self-Medication. The Hague, The Netherlands: WHO.

Zeenot, S. (2013). Pengelolaan dan Penggunaan Obat Wajib Apotek. Yogyakarta. D-Medika. 